\title{
Malignant Germinative Follicular Epithelium Neoplasm
}

National Cancer Institute

\section{Source}

National Cancer Institute. Malignant Germinative Follicular Epithelium Neoplasm. NCI

Thesaurus. Code C43321.

A malignant neoplasm that arises from germinative follicular epithelial cells. 